\title{
Surface modification of banana fibers using organosilanes: an IGC insight
}

\author{
Emanuel Alonso $\cdot$ Laly A. Pothan - Artur Ferreira • Nereida Cordeiro $\mathbb{C}$
}

Received: 12 September 2018/ Accepted: 21 February 2019

(C) Springer Nature B.V. 2019

\begin{abstract}
Banana fibers are an agricultural waste material with a great exploitation potential due to their cellulose-rich content. Raw banana fibers (RBF) were treated with 3-aminopropyltriethoxy silane and glycidoxypropyltrimethoxy silane to improve the inherent limitations of banana fibers, namely its poor cell adhesion. The fibers' modification was evaluated by inverse gas chromatography (IGC). Similar $\gamma_{s}^{d}$ values were observed between the RBF and silane-treated fibers $\left(39-41 \mathrm{~mJ} / \mathrm{m}^{2}\right)$, which indicates similar reactivity towards apolar probes. However, the decrease in the entropic parameter indicates the silane covalent bonding with the cellulose chains making a stiffer
\end{abstract}

structure. Organosilane grafting was confirmed by an increased basic character in the silane-treated fibers $\left(K_{b} / K_{a}\right.$ from 1.03 to 2.81$)$. The surface morphology also changed towards higher contact area $\left(S_{B E T}\right.$ increases 6.7 times) and porosity ( $D p$ increases up to $67 \%$ ). Both morphological and functional group reactivity changes suggest that the organosilane treatment offers new opportunities for these fibers to be used as adsorbents for proteins as well as to cell adhesion. Therefore, IGC proved a simple and viable technique in the characterization of silane-treated fibers.
E. Alonso $\cdot$ N. Cordeiro $(\square)$

LB3, Faculty of Science and Engineering, University of Madeira, 9000-390 Funchal, Portugal

e-mail: ncordeiro@staff.uma.pt

L. A. Pothan

Department of Chemistry, Bishop Moore College,

Mavelikara, Kerala 690110, India

A. Ferreira

CICECO - Aveiro Institute of Materials and Águeda

School of Technology and Management, University of

Aveiro, 3754-909 Águeda, Portugal

N. Cordeiro

CIIMAR - Interdisciplinary Centre of Marine and

Environmental Research, University of Porto,

4450-208 Matosinhos, Portugal 


\section{Graphical abstract}

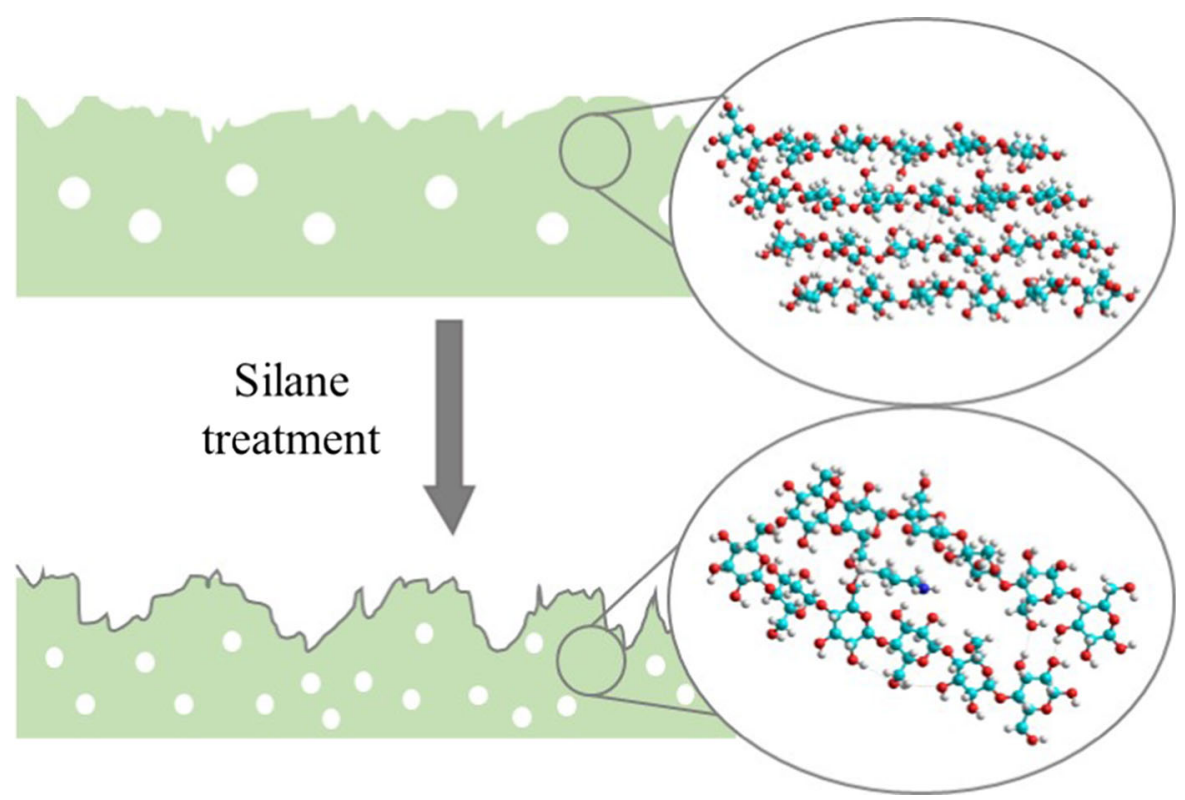

Keywords Banana fibers · Organosilane coupling agent - Inverse gas chromatography $\cdot 3$ -

Aminopropyltriethoxy silane .

Glycidoxypropyltrimethoxy silane

\section{Introduction}

The use of bio-based renewable materials has been the focus of the scientific community towards all environmental preservation and sustainability of resources. Natural fibers such as those from banana fibers, offer several advantages: they are plentiful, biodegradable, present low health hazards and possess a relatively high tensile strength (Xie et al. 2010).

Although natural fibers present potential to be applied as a reinforcement material, the hydrophilic character attributed to the rich hydroxyl surface can limit the applications due to the low compatibility with non-polar matrices such as resins, polypropylene and polyethylene, and to cell adhesion (Abdelmouleh et al. 2002). Hence, it is of great interest to overcome the drawbacks of natural fibers through surface functionalization, such as by using organosilanes.

Organosilanes or silanes are usually applied as coupling agents between glass fibers and polymer matrices and present the general formula of $\mathrm{R}-\mathrm{Si}-$
$(\mathrm{X})_{3}$, where $\mathrm{R}$ corresponds to the organic functional group and $\mathrm{X}$ represents the oxyalkyl group (Abdelmouleh et al. 2002). The chemical grafting of the silane onto the surface of the fibers (Fig. 1) encompasses the following steps: (1) the hydrolysis of the silane alkoxy groups onto silanol; (2) the adsorption of the silanol groups onto the $\mathrm{OH}$-rich surface of the fibers through hydrogen bonding and (3) chemical condensation leading to siloxane bridges ( $\mathrm{Si}-\mathrm{O}-\mathrm{Si}$ ) and grafting onto the surface of the fibers through $\mathrm{Si}-$ $\mathrm{O}-\mathrm{C}$ bonds (Thakur et al. 2013a, b, c, d, 2014a, b, 2016; Khanjanzadeh et al. 2018).

Several works have been done with the aim to study and evaluate the interaction between natural fibers and the silanes (Robles et al. 2018; Pujiasih et al. 2018; Mohd et al. 2016; Gwon et al. 2010). Salon et al. (2007) evaluated the changes of both these materials by liquid and solid-state NMR, evaluating the kinetics of silane hydrolysis by ${ }^{1} \mathrm{H}$ NMR spectra, as well as the resulting composite by different ${ }^{13} \mathrm{C}$ NMR methods. Also, the same authors have previously studied the adsorption isotherms of silanes onto the fibers (Salon et al. 2005). Taokaew et al. (2015), Fernandes et al. (2013) and Frone et al. (2018) modify bacterial cellulose with silanes in order to promote new materials for different applications, such as food packaging and to cell adhesion of human fibroblast 
Fig. 1 Schematic presentation of the reaction mechanism of silanecellulose grafting process. i Hydrolysis; ii hydrogen bond formation; iii covalent bond formation

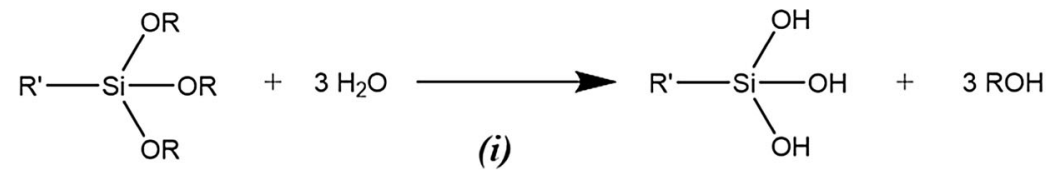<smiles>[R][Si](O)(O)O</smiles><smiles>[R][Si](O)(O)O[C@H](C)O[CH]</smiles><smiles>[R][Si](O)(O)O[Co][Co]</smiles><smiles>[R][Si](O)(O)O[GeH3]</smiles>

onto the fibers (observing an enhancement in cell attachment and proliferation using 3-aminopropyltriethoxy silane modified bacterial cellulose). Moreover, Ifuku and Yano (2015) evaluated the mechanical properties of the silane-treated fibers, observing an increase of the Young's Modulus upon increasing silane concentrations, and therefore an increased stiffness of the fibers. The fibers' modification generates new materials with different properties at the morphological, mechanical and thermal level. The assessment of surface properties is important to predict the interaction of these materials with other interfaces, such as cell adhesion of human fibroblast, food packaging or adsorbents.

Inverse gas chromatography (IGC) is an analytical technique that has been applied recently as a reliable source of physicochemical data for many non-volatile materials. This technique can be applied to an array of materials, namely to natural and treated fibers. For instance, the effect of saponin onto the surface properties of banana fibers was studied by Cordeiro et al. (2013), where changes in the interaction of the surface active sites toward polar probes, as well as in the surface morphology, were observed. Deepa et al. (2015) also extracted nanocellulose from several lignocellulosic sources, including banana fibers. This was studied with IGC, where the effect of bleaching and acid hydrolysis into raw fibers was highlighted.

Following our interest on assessing the surface properties of unmodified and modified materials, the aim of the present work was to employ an efficient, fast and simple methodology, the IGC, to measure and understand the changes in the surface properties caused by the material modifications. Thus, raw banana fibers were functionalized with 3-aminopropyltriethoxy silane (APS) and glycidoxypropyltrimethoxy silane (GPS), using a simple and direct method, which should provide new properties to the resulting material. These properties were evaluated by IGC. The literature reports the functionalization of cellulosic and non-cellulosic materials with organosilanes compounds (Abdelmouleh et al. 2002; Ifuku and Yano 2015; Khanjanzadeh et al. 2018; Salon et al. 2007; Taokaew et al. 2015; Xie et al. 2010). This work complements and understands data obtained by other authors, and also tests the versatility and applicability of the IGC technique to study the modification of fibers.

\section{Materials and methods}

Organosilane chemical treatment

Raw banana fibers (RBF) were extracted from the pseudo-stem of the banana plant Musa sapientum, collected from Marthandam, Tamil Nadu, India. Organosilane-treated fibers were obtained by treating the fibers with either $5 \mathrm{wt} \%$ of APS or $5 \mathrm{wt} \%$ of GPS (silane weight percentage compared to the fiber weight) in a mixture of water-ethanol (40:60, v/v). The chemical structure of the silanes can be found in Fig. 2. The $\mathrm{pH}$ of the solution was adjusted to 4 , with acetic acid and stirred continuously for $1 \mathrm{~h}$. Then, the fibers were soaked in the solution for $3 \mathrm{~h}$ and kept in air for $24 \mathrm{~h}$. The treated fibers were oven dried at 

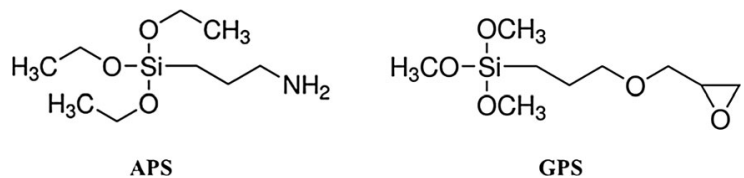

Fig. 2 Structure of aminopropyltriethoxy silane (APS) and glycidoxypropyl silane (GPS)

$80{ }^{\circ} \mathrm{C}$ for $24 \mathrm{~h}$. The samples were named APSBF and GPSBF, accordingly to the silane coupling agent added.

Fourier transformed infrared spectrometer coupled with attenuated total reflectance (FTIR-ATR) characterization

FTIR-ATR spectra of the samples were obtained with a Perkin Elmer Spectrum Two coupled with a Diamond ATR accessory (DurasamplIR II, Smiths Detection, UK). 36 scans were acquired in the range of $4000-650 \mathrm{~cm}^{-1}$, with a wavenumber resolution of $4 \mathrm{~cm}^{-1}$.

Solid-state cross-polarization magic angle spinning 13carbon nuclear magnetic resonance (CPMAS ${ }^{13} \mathrm{C}$ NMR) characterization

CPMAS ${ }^{13} \mathrm{C}$ NMR spectra were recorded on a Bruker Advance III 400 spectrometer operating at a B0 field of $9.4 \mathrm{~T}$ using $12 \mathrm{kHz}$ MAS with proton $90^{\circ}$ pulse of 3 microseconds and a time between scans of $3 \mathrm{~s} .{ }^{13} \mathrm{C}$ CPMAS NMR spectra were acquired using a contact time of $2000 \mu \mathrm{s} .{ }^{13} \mathrm{C}$ chemical shifts were referenced with respect to glycine $(\mathrm{C}=\mathrm{O}$ at $176.03 \mathrm{ppm})$.

Inverse gas chromatography measurements (IGC)

The measurements were carried out on a commercial inverse gas chromatograph (Surface Measure Systems London, UK), equipped with both FID and TCD detectors. The system was automated with the Software SMS iGC Controller v1.8. Silanized glass columns with $3 \mathrm{~mm}$ inner diameter and $300 \mathrm{~mm}$ length (dimethyldichlorosilane, Repelcote BDH, UK) and packed through vertical tapping. The samples were conditioned overnight at $40{ }^{\circ} \mathrm{C}$ followed by $2 \mathrm{~h}$ at the temperature used for analysis.

The measurements were made under infinite dilution conditions, where the adsorbate/adsorbate interactions are negligible and therefore only the adsorbate/adsorbent interaction are measured. Moreover, under these conditions, the probe molecules interact with the energetic active sites, following Henry's Law. In that region, one should expect symmetrical Gaussian peaks.

The probes were supplied by Sigma Aldrich, with analytic grade (>99\%). Methane was used as an inert reference gas, being supplied, alongside Helium, by Air Liquide Company, with a purity above $99 \%$. The physical constants used in IGC were taken from Alonso et al. (2018) and are displayed in Table 1.

\section{Dispersive surface energy}

Dispersive surface energy measurements were carried out using a series of $n$-alkanes, from heptane to decane, at 20,25 and $30{ }^{\circ} \mathrm{C}, 0 \% \mathrm{RH}$, with a $10 \mathrm{~mL} /$ min flow rate of Helium and at $0.2 \mathrm{p} / \mathrm{p}_{0} \quad\left(p_{0}\right.$ corresponds to the gas pressure, $p$ the adsorbate pressure). The dispersive component was determined following Schultz et al. (1987), by applying the Eq. 1, where: $\Delta G^{d}$ is the Gibbs free energy of adsorption of the dispersive component; $R$ the universal gas constant; $T$ the temperature; $V_{g}$ the gas volume; $N_{A}$ Avogadro's constant; $a_{m}$ the cross-sectioned area of the adsorbate; $\gamma_{s}^{d}$ the dispersive component of the material's surface energy; $\gamma_{L}^{d}$ the probe surface tension and $K$ a constant.

$\Delta \mathrm{G}^{\mathrm{d}}=\mathrm{RT} \ln \left(\mathrm{V}_{\mathrm{g}}\right)=2 \mathrm{~N}_{\mathrm{A}} \cdot\left(\gamma_{\mathrm{S}}^{\mathrm{d}}\right)^{\frac{1}{2}} \cdot \mathrm{a}_{\mathrm{m}}\left(\gamma_{\mathrm{L}}^{\mathrm{d}}\right)^{\frac{1}{2}}+\mathrm{K}$

\section{Specific surface energy}

In the case of polar molecules, the free energy of adsorption is above the $n$-alkane straight-line, since both dispersive and specific interactions take place between the surface and the adsorbate. Thus, specific interactions correspond to the vertical distance between the polar adsorbate and the alkane line (Thielmann 2004). From the specific free energy of adsorption, it is possible to obtain the surface donor $\left(\gamma_{S}^{-}\right)$and acceptor $\left(\gamma_{S}^{+}\right)$numbers, based on the GoodVan Oss concept (Oss 1988). Experimentally, one should use two probe monopolar molecules: an acid one and a basic one. This way, it is possible to obtain the parameters indicated above (Goss 1997) from Eq. 2, where $\gamma_{L}^{+}$and $\gamma_{L}^{-}$are the acceptor and donor 
Table 1 Physical constants of the applied probes in inverse gas chromatograph $\gamma_{l}^{d}$ : liquid surface tension; a: cross section surface area; $D N$ and $A N^{*}$ : electron donor and acceptor numbers; $\gamma_{l}^{+}$and $\gamma_{l}^{-}$: surface acceptor and donor numbers

\begin{tabular}{lllllll}
\hline Probe & $\begin{array}{l}\gamma_{l}^{d} \\
\left(\mathrm{~mJ} / \mathrm{m}^{2}\right)\end{array}$ & $\begin{array}{l}\mathrm{a} \\
\left(10^{-19} \mathrm{~m}^{2}\right)\end{array}$ & $\begin{array}{l}\mathrm{DN} \\
(\mathrm{kcal} / \mathrm{mol})\end{array}$ & $\begin{array}{l}\mathrm{AN} \\
(\mathrm{kcal} / \mathrm{mol})\end{array}$ & $\begin{array}{l}\gamma_{l}^{+} \\
\left(\mathrm{mJ} / \mathrm{m}^{2}\right)\end{array}$ & $\begin{array}{l}\gamma_{l}^{-} \\
\left(\mathrm{mJ} / \mathrm{m}^{2}\right)\end{array}$ \\
\hline Decane & 0.0234 & 7.50 & - & - & - & - \\
Nonane & 0.0227 & 6.90 & - & - & - & - \\
Octane & 0.0213 & 6.30 & - & - & - & - \\
Heptane & 0.0203 & 5.73 & - & - & - & - \\
THF & 0.0225 & 2.90 & 20.00 & 0.50 & - & - \\
DCM & 0.0245 & 2.45 & - & 3.90 & 124.58 & 0 \\
AC & 0.0165 & 3.40 & 17.00 & 2.50 & - & - \\
EtAc & 0.0196 & 3.30 & 17.10 & 1.50 & 0 & 457.67 \\
ACN & 0.0275 & 2.14 & 14.10 & 4.70 & - & - \\
\hline
\end{tabular}

numbers of the adsorbate and $\Delta G^{s p}$ the Gibbs specific free energy of adsorption.

$\Delta \mathrm{G}^{\mathrm{sp}}=2 \mathrm{~N}_{\mathrm{A}} \mathrm{a}_{\mathrm{m}}\left(\sqrt{\gamma_{\mathrm{S}}^{-} \gamma_{\mathrm{L}}^{+}}+\sqrt{\gamma_{\mathrm{S}}^{+} \gamma_{\mathrm{L}}^{-}}\right)$

After obtaining the donor and acceptor numbers of the surface, it is possible to estimate the specific free energy of adsorption $\left(\gamma_{s}^{s p}\right)$, from Eq. 3, which corresponds to the geometric mean of these parameters:

$\gamma_{\mathrm{s}}^{\mathrm{sp}}=2 \sqrt{\gamma_{\mathrm{s}}^{-} \gamma_{\mathrm{S}}^{+}}$

With both dispersive and specific surface energies, the total surface energy $\left(\gamma_{s}^{\text {total }}\right)$, corresponding to the sum of the two components is obtained.

\section{Acid/base character}

For the specific surface energy and acid/base character studies, tetrahydrofuran (THF), dichloromethane (DCM), acetone (AC), ethyl acetate (EtAc) and acetonitrile $(\mathrm{ACN})$ were used in the IGC measurements. The measurements were carried out at 20, 25 and $30{ }^{\circ} \mathrm{C}, 0 \% \mathrm{RH}$, with a $10 \mathrm{~mL} / \mathrm{min}$ flow rate of Helium and at $0.2 \mathrm{p} / \mathrm{p}_{0}$. The $K_{a}$ and $K_{b}$ constants were determined from Eq. 4, which, by plotting the results, the slope should correspond to $K_{a}$, while the y-axis intercept corresponds to $K_{b}$.

$$
\left(\Delta \mathrm{G}^{\mathrm{sp}} / \mathrm{AN}^{*}\right)=K_{a}\left(\mathrm{DN} / \mathrm{AN}^{*}\right)+K_{b}
$$

\section{Isotherm measurement}

The $n$-octane isotherm measurements were performed in the IGC at $25^{\circ} \mathrm{C}$ at different concentrations, between 0.05 and $0.2 \mathrm{p} / \mathrm{p}_{0}$, with a $10 \mathrm{~mL} / \mathrm{min}$ flow rate. These measurements allowed to obtain the $n$ octane heterogeneity profile. In order to obtain the monolayer capacity $\left(n_{m}\right)$ of the sample, Eq. 5, developed by Brunauer et al. (1938), was applied, where $n$ corresponds to the amount of probe adsorbed and $c$ is a constant.

$\left.\mathrm{p} / \mathrm{n}\left(\mathrm{p}_{0}-\mathrm{p}\right)=(c-1) /\left(\mathrm{n}_{\mathrm{m}} c\right)\right) *\left(p / \mathrm{p}_{0}\right)+\left(1 /\left(\mathrm{n}_{\mathrm{m}} c\right)\right.$

In this way, it is possible to obtain the BET surface area $\left(S_{B E T}\right)$ by Eq. 6:

$\mathrm{S}_{\mathrm{BET}}=a \mathrm{n}_{\mathrm{m}} \mathrm{N}_{\mathrm{A}}$

\section{Diffusion parameter}

In diffusion analysis, different flow rates of mobile gas are used. The diffusion coefficient can be obtained from the width of the elution peak through Eq. 7, where $H$ is the height equivalent to the theoretical plate $(\mathrm{cm})$ and $u$ is the carrier gas speed $(\mathrm{cm} / \mathrm{s})$.

$\mathrm{H}=\mathrm{A}+(\mathrm{B} / \mathrm{u})+\mathrm{Cu}$

Parameter $A$ is called Eddy diffusion and is related to the size of support particles and irregularity of packing. Parameter $B$ describes the longitudinal diffusion of the probe along the stream of carrier gas. The third parameter $(C)$ is related to peak broadening, which is due to the mass resistance within the column. Using the constant $C$, the diffusion coefficient $(D p)$ is obtained through Eq. 8, where $K$ is the partition ratio and $d$ the film thickness (Jackson and Huglin 1995). 


$$
\mathrm{C}=\left(\frac{8}{\pi}\right) *\left[\mathrm{~K} /(1+\mathrm{K})^{2}\right] *\left(\mathrm{~d}^{2} / \mathrm{Dp}\right)
$$

\section{Statistical analysis}

The statistical analysis of the data was carried out using the IBM SPSS Statistics 23 software. Differences in the measurements of a given parameter were assessed by one-way analysis of variance (ANOVA), followed by a Tukey's post hoc analysis. For IGC, the error of the measurements was $3 \%$ and the average values were presented. $p$ values of $<0.05$ were considered statistically different.

\section{Results and discussion}

Banana fibers were functionalized with two organosilanes: APS and GPS in order to promote the compatibility with the hydrophobic matrices as well as to reduce the moisture capacity to preserve the inherent mechanical properties of cellulose. The functionalized cellulose fibers were obtained through a simple, direct and environmentally friendly method. The organosilanes-treated fibers were evaluated structurally and chemically, as well as the surface reactivity.

FTIR analyses were made to obtain information about the covalent bond between the silanes and the raw fibers. The FTIR spectrum (Fig. 3) of raw banana display typical absorption peaks of cellulose at around
$3324 \mathrm{~cm}^{-1}$ (O-H stretching vibrations), $2893 \mathrm{~cm}^{-1}$ (C-H symmetrical stretching vibration), $1636 \mathrm{~cm}^{-1}$ (O-H bending vibrations of absorbed water) and between 1424 and $1319 \mathrm{~cm}^{-1}$ assigned to the symmetric bending of $\mathrm{CH}_{2}$, bending vibrations of the $\mathrm{C}-\mathrm{H}$ and $\mathrm{C}-\mathrm{O}$ groups of the polysaccharides rings (Xie et al. 2010; Abdelmouleh et al. 2002; Mohd et al. 2016; Gwon et al. 2010). Besides that, the bands present at about $1158 \mathrm{~cm}^{-1}$ are assigned to the $\mathrm{C}-\mathrm{O}-\mathrm{C}$ bond of the ether group found within the glucopyranose ring and between the glucose monomers (Fan et al. 2012). Moreover, a peak can be observed at $1733 \mathrm{~cm}^{-1}$, which indicates the presence of hemicellulose (Cordeiro et al. 2011). After the chemical modification of banana fibers with APS and GPS, a slight increase of $\mathrm{Si}$ specific peaks around $1160-1104 \mathrm{~cm}^{-1}$ and at $700 \mathrm{~cm}^{-1}$, which fact was attributed to $\mathrm{Si}-\mathrm{O}-\mathrm{Si}$ and $\mathrm{Si}-\mathrm{O}-\mathrm{C}$ symmetric stretching. These two respectively indicated that the organosilanes were successfully incorporated onto the surface of banana fibers. These peaks are overlapped with the intense $\mathrm{C}-\mathrm{O}-\mathrm{C}$ vibration bands of cellulose in the same spectral region (Khanjanzadeh et al. 2018; Mohd et al. 2016; Gwon et al. 2010). Furthermore, the disappearance of the peak at $1244 \mathrm{~cm}^{-1}$ (assigned to $\mathrm{C}-\mathrm{OH}$ bending vibrations in plane at C6) and the high increase of the peak at $1189 \mathrm{~cm}^{-1}$ (attributable to $\mathrm{Si}-\mathrm{C}$ bond), is indicative of a reaction between organosilanes and cellulose (Abdelmouleh et al. 2004; Gwon et al. 2010). Moreover, a slight increase in the specific peaks around
Fig. 3 FTIR spectra of raw banana fibers (RBF) and silane-treated banana fibers with APS (APSBF) and GPS (GPSBF)

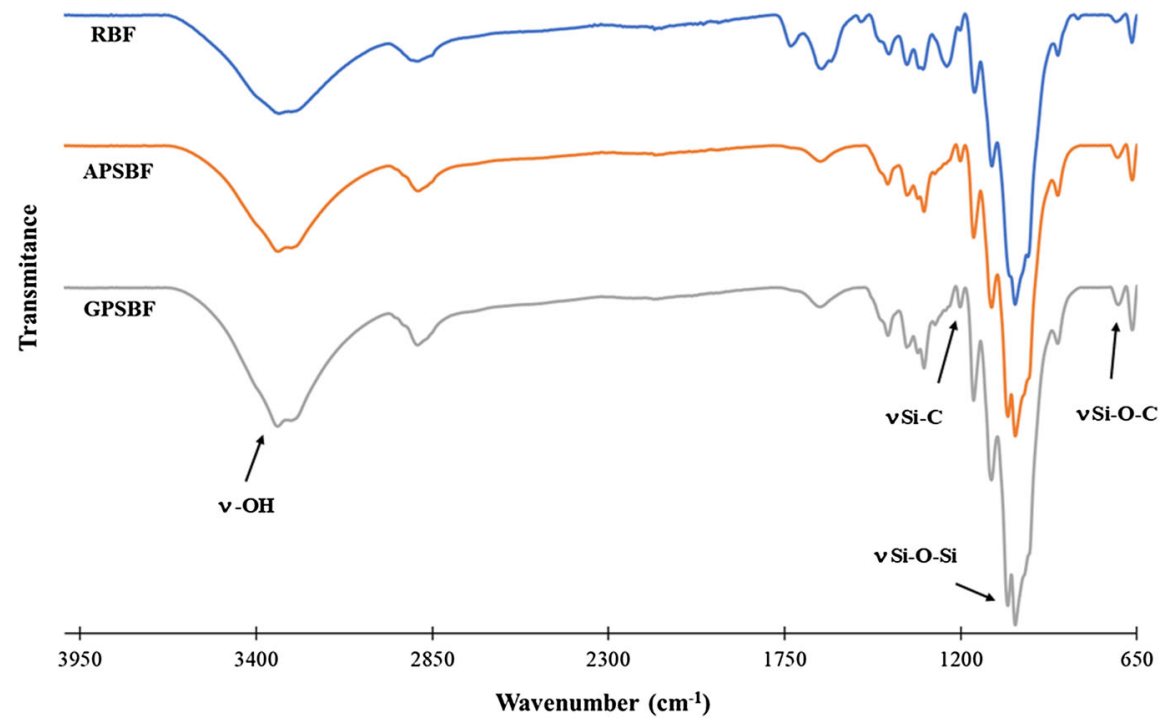


$3591-3200 \mathrm{~cm}^{-1}, 1600-1580 \mathrm{~cm}^{-1}$ and $1118 \mathrm{~cm}^{-1}$, assigned as $\mathrm{N}-\mathrm{H}$ stretching and bending vibrations, respectively, of the APS chemical reagent (Mohd et al. 2016), were observed.

Solid-state ${ }^{13} \mathrm{C}$ NMR measurements were also performed to provide/confirm information regarding the structural features in the cellulose fibers and silane modified fibers. Figure 4 shows the CPMAS ${ }^{13} \mathrm{C}$ NMR analysis of raw and modified RBF with APS and GPS. The spectra showed the six well visible signals in the 107-62 ppm range, attributed to the structure of cellulose network: $62-65 \mathrm{ppm}$ assigned to carbon C6, which the signal split into a contribution of the amorphous non-hydrolysed cellulose at $62 \mathrm{ppm}$ and of the crystalline part at $64 \mathrm{ppm} ; 71-77 \mathrm{ppm}$ corresponding to carbons $\mathrm{C} 2, \mathrm{C} 3$ and $\mathrm{C} 5$, which contribute to the $\beta(1-4)$ linkage; $85-90 \mathrm{ppm}$ assigned to 104-107 ppm corresponding to carbon C1 (Robles et al. 2018; Khanjanzadeh et al. 2018). After chemical modification with APS, new peaks were displayed corresponding to the characteristic signals of APS at $55.8,46.1$ and $20.7 \mathrm{ppm}$ assigned to the $\mathrm{O}-\mathrm{CH}_{2}-\mathrm{CH}_{3}$, $\delta-\mathrm{CH}_{2}$ and $\beta-\mathrm{CH}_{2}$ resonances (Khanjanzadeh et al.
2018; Robles et al. 2018). In GPS's case, its characteristic chemical shifts were shown to have a lower magnitude at 57.0, 22.8 and $5.6 \mathrm{ppm}$ attributed to $\mathrm{CH}_{2}(\mathrm{OH})-\mathrm{CH}(\mathrm{OH})-\mathrm{CH}_{2}, \mathrm{CH}_{2}-\mathrm{O}-\mathrm{Si}$ and $\mathrm{CH}_{2} \mathrm{OH}$ resonance (Hoebbel et al. 1998). The presence of these peaks in the silane-treated fibers supported the FTIR data reporting a successful reaction of silanes with cellulose chains.

Silane-treated fibers surface characterization

The implementation of IGC in the analysis of the silane-treated fibers offers the opportunity to study the interactions between probe molecules with different properties and the surface of the samples. Thus, linear alkane probes will be used to determine the dispersive (van der Waals) interactions, while a series of polar probes will be used to determine the acid-base character changes upon organosilane treatment.
Fig. 4 CPMAS ${ }^{13} \mathrm{C}$ NMR spectra of raw banana fiber (RBF) and silane-treated fibers with APS (APSBF) and GPS (GPSBF)

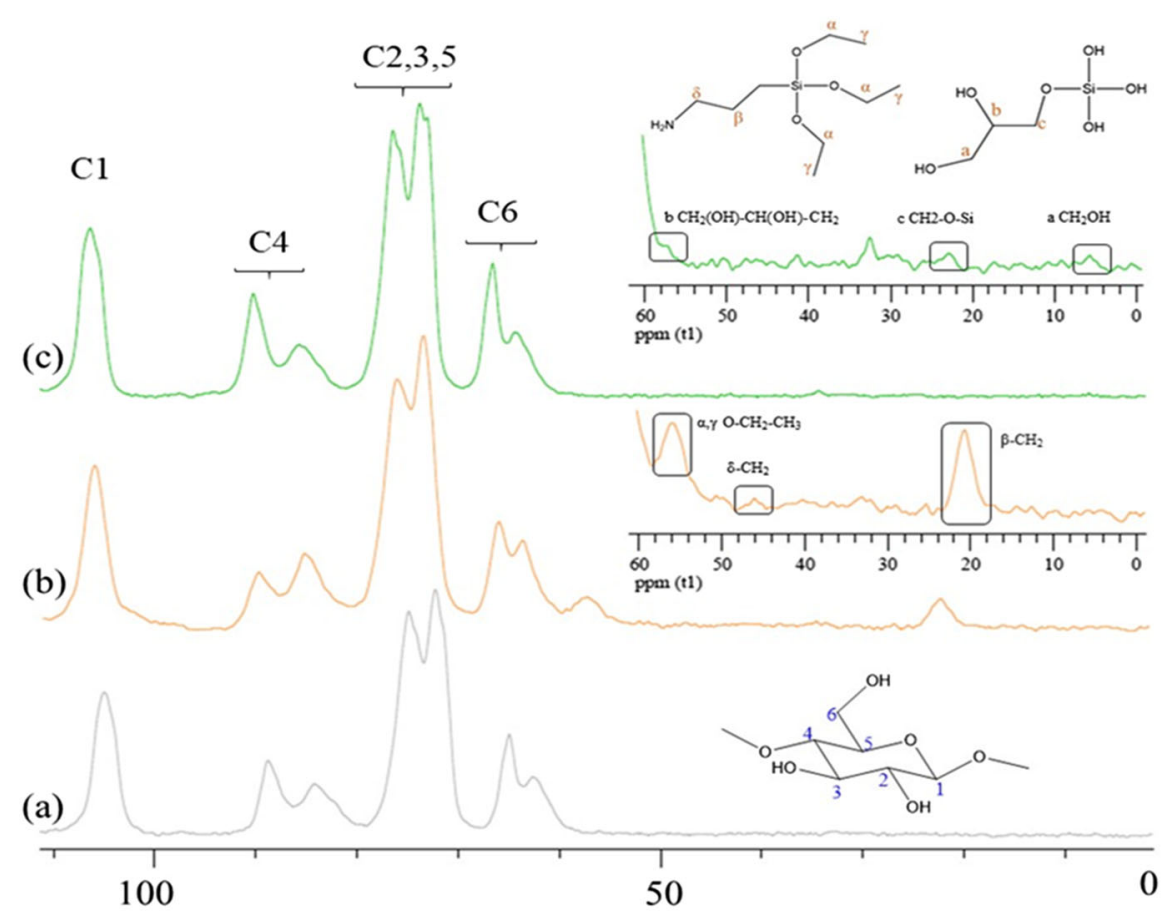

Chemical Shift (ppm) 
Surface energy

The IGC data regarding the surface energy parameters (Eq. 1) of the samples can be found in Table 2 and Fig. 5. Raw banana fibers (RBF) present a $\gamma_{s}^{d}$ value of $39.49 \mathrm{~mJ} / \mathrm{m}^{2}$ at $25{ }^{\circ} \mathrm{C}$, which is similar to the values found in literature, such as in Cordeiro et al. (2013), where microcellulose extracted from banana had a $\gamma_{s}^{d}$ value of $39.90 \mathrm{~mJ} / \mathrm{m}^{2}$. Also, Mills et al. (2008) studied different natural fibers, presenting a surface energy between 36 and $44 \mathrm{~mJ} / \mathrm{m}^{2}$ at $20{ }^{\circ} \mathrm{C}$, which includes the values obtained in the current work at the same temperature.

With the organosilane treatments, the banana fiber did not suffer significant changes in the $\gamma_{s}^{d}$ values. Although, similar surface energy values do not necessarily mean equal surfaces, since the resulted $\gamma_{s}^{d}$ value is influenced by the amount and energy of the active sites that interact with the probe at the surface. Thus, the heterogeneity profile of $n$-octane was determined and an increase is observed in the number of high-energy active sites, with a substantial decrease in the number of low-energy active sites upon organosilane treatment (Fig. 6). This is because the native groups of the fibers became partially inaccessible, which lowered the amount of interactions with the surface non-polar active sites, as well as the partial substitution of the hydroxyl groups into the silane, which slightly increased adsorption potential.

Regarding the decrease of the surface energy with the temperature (Fig. 5), it was determined that the $\Delta \gamma_{s}^{d} / \Delta T$ presents a negative trend due to the thermodynamics of adsorption. Being an exothermic phenomenon, according to the Le Chatelier's principle, increasing the temperature makes adsorption less favourable. Thus, with increasing temperature, the interactions between the adsorbate and the surface are reduced, leading to lower $\gamma_{s}^{d}$ values. Upon the organosilane treatments, the fibers present lower influence of the temperature on the surface energy value $(p<0.05)$. This indicates that after the organosilane covalent bonding with the fiber, there was an overall decrease in the degrees of freedom, meaning that the organosilane grafted could hinder the movement of the cellulose chains, therefore making a stiffer surface. This observation goes in accordance with the study made by Ifuku and Yano (2015), where the silane treatment led into lower Young Modulus values, and therefore lower elasticity of the fibers.

\section{Surface acid-base interactions}

Concerning the specific interactions that the sample can establish, a series of polar probes were injected, at different temperatures, and the respective specific free energies of adsorption $\left(\Delta G_{s}^{s p}\right)$ obtained can be found in Table 3 and Fig. 7. The $\Delta G_{s}^{s p}$ values cannot be compared between probes, because they depend on them. But the comparison of the same probe before and after modification can give information about surface acid-base changes. Although the probes have the same tendency, the magnitude of the variations are different. Increased interactions can be observed with ethyl acetate (up to $8 \%$ ), acetonitrile (up to $31 \%$ ) and acetone (up to $7 \%$ ), while on the other hand with dichloromethane (up to 10\%) and tetrahydrofuran (up to $18 \%$ ), the interactions had decreased. This indicates that the organosilane treatment functionalized the fibers and therefore alters its reactivity towards to polar probes.

Regarding the acid/base surface character, the $K_{a}$ and $K_{b}$ values were determined using Eq. 4 (Table 2).

Table 2 Surface energy parameters, surface area, diffusion coefficient and acid/base parameters to raw and silane-treated banana fibers with 3-aminopropyltriethoxy silane (APSBF) and glycidoxypropyltrimethoxy silane (GPSBF), at $25^{\circ} \mathrm{C}$

\begin{tabular}{llllllllll}
\hline Sample & $\begin{array}{l}\gamma_{s}^{d} \\
\left(\mathrm{~mJ} / \mathrm{m}^{2}\right)\end{array}$ & $\begin{array}{l}\Delta \gamma_{s}^{d} / \Delta T \\
\left(\mathrm{~mJ} / \mathrm{m}^{2} \mathrm{~K}\right)\end{array}$ & $\begin{array}{l}\gamma_{s}^{s p} \\
\left(\mathrm{~mJ} / \mathrm{m}^{2}\right)\end{array}$ & $\begin{array}{l}\gamma_{s}^{\text {total }}\left(\mathrm{mJ} / \mathrm{m}^{2}\right) \\
\left(\mathrm{m}^{2}\right.\end{array}$ & $K_{a}$ & $K_{b}$ & $K_{b} / K_{a}$ & $\begin{array}{l}S_{B E T} \\
\left(\mathrm{~m}^{2} / \mathrm{g}\right)\end{array}$ & $\begin{array}{l}D p \\
\left(\mathrm{~cm}^{2} / \mathrm{min}\right)\end{array}$ \\
\hline RBF & $39.49^{\mathrm{a}}$ & $-0.24^{\mathrm{a}}$ & $40.65^{\mathrm{a}, \mathrm{b}}$ & $80.14^{\mathrm{a}}$ & $0.11^{\mathrm{a}}$ & $0.11^{\mathrm{a}}$ & $1.03^{\mathrm{a}}$ & $0.23^{\mathrm{a}}$ & $0.09^{\mathrm{a}}$ \\
APSBF & $39.23^{\mathrm{a}}$ & $-0.19^{\mathrm{b}}$ & $37.38^{\mathrm{a}}$ & $76.60^{\mathrm{a}}$ & $0.09^{\mathrm{b}}$ & $0.23^{\mathrm{b}}$ & $2.58^{\mathrm{b}}$ & $1.45^{\mathrm{b}}$ & $0.15^{\mathrm{b}}$ \\
GPSBF & $41.21^{\mathrm{a}}$ & $-0.11^{\mathrm{c}}$ & $42.27^{\mathrm{a}, \mathrm{b}}$ & $83.47^{\mathrm{a}}$ & $0.09^{\mathrm{b}}$ & $0.26^{\mathrm{b}}$ & $2.81^{\mathrm{b}}$ & $1.54^{\mathrm{b}}$ & $0.13^{\mathrm{b}}$ \\
\hline
\end{tabular}

Values in same column not sharing a common superscript are statistically different $(p<0.05)$; $\gamma_{s}^{d}$ : dispersive component of surface energy; $\Delta \gamma_{s}^{d} / \Delta T$ : temperature dependence of the surface energy; $\gamma_{s}^{s p}$ : specific component of the surface energy; $\gamma_{S}^{\text {total }}$ : total surface energy; $K_{a}$ : acidity constant; $K_{b}$ : basicity constant; $S_{B E T}$ : surface area; $D p$ : diffusion coefficient 
Fig. 5 Dispersive surface energy plot of raw (RBF) and silane-treated banana fibers with

3-aminopropyltriethoxy silane (APSBF) and glycidoxypropyltrimethoxy silane (GPSBF), at $25^{\circ} \mathrm{C}$
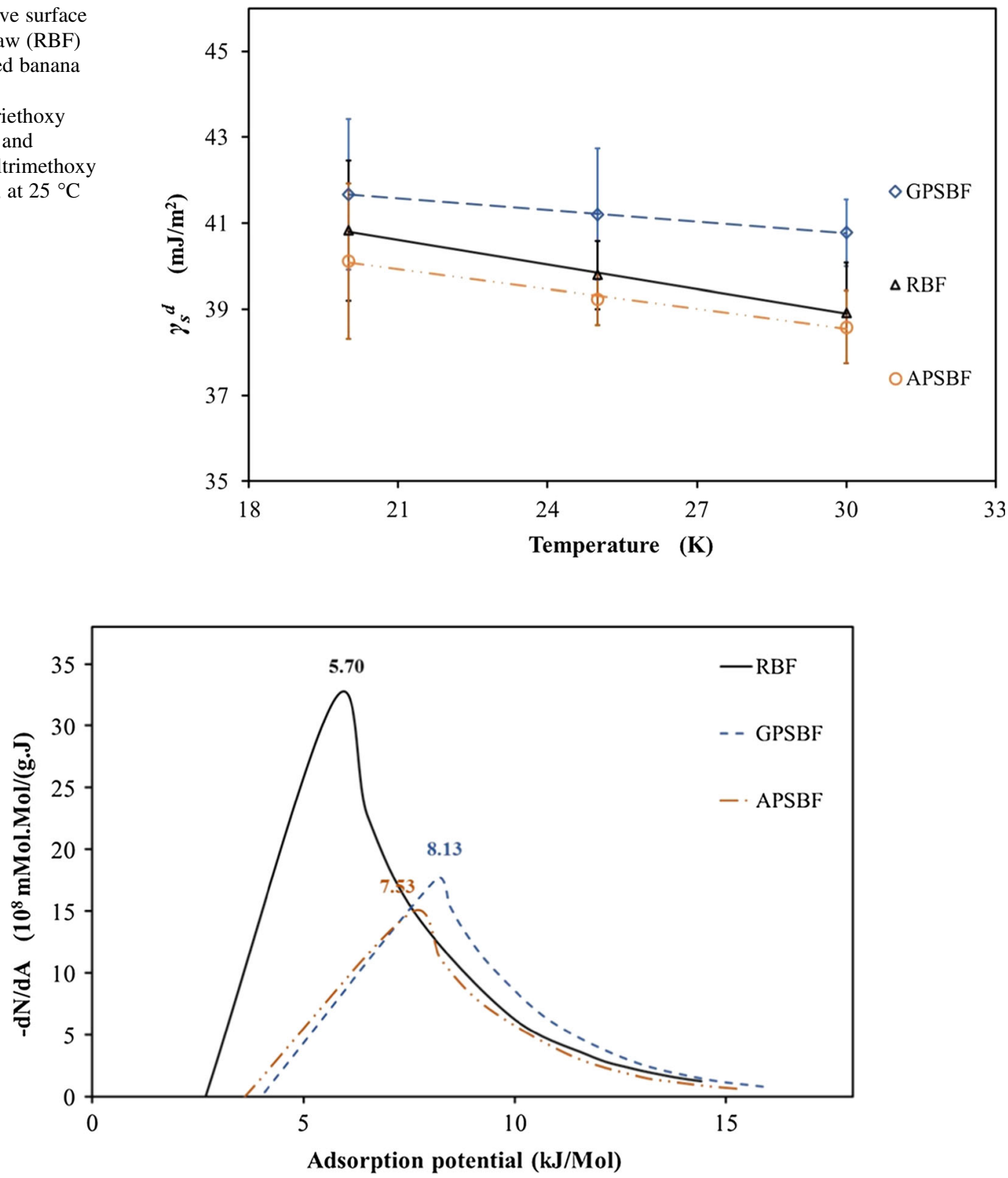

Fig. 6 n-octane heterogeneity profile of raw (RBF) and silane-treated banana fibers with 3-aminopropyltriethoxy silane (APSBF) and glycidoxypropyltrimethoxy silane (GPSBF), at $25^{\circ} \mathrm{C}$

A significant increase in the surface basicity is observed upon the organosilane treatments $\left(K_{b} / K_{a}\right.$ increases up to $173 \%$ ), which was related to the decreased amount of hydroxyl groups present (therefore, lower $K_{a}$ values) and increased C-O-Si and $\mathrm{Si}-$ $\mathrm{O}-\mathrm{Si}$ bonds (increased $K_{b}$ values) that occurred with organosilane grafting (Fig. 1iii). Moreover, taking into consideration the functional groups present in the silane molecules, when the chemical bond between the fiber and the coupling agent occurs, the resulting material presents amine (in case of APSBF) or epoxy ring (in case of GPSBF), which further increases the basic character (Fig. 2). 
Table 3 Specific free energies of adsorption $\left(\Delta G^{s p}\right)$ to raw (RBF) and silane-treated banana fibers with 3-aminopropyltriethoxy silane (APSBF) and glycidoxypropyltrimethoxy silane (GPSBF)

\begin{tabular}{lllllll}
\hline Sample & $\mathrm{T}\left({ }^{\circ} \mathrm{C}\right)$ & \multicolumn{5}{c}{$\Delta G^{s p}\left(\mathrm{~kJ} / \mathrm{m}^{2}\right)$} \\
\cline { 3 - 7 } & & THF & DCM & AC & EtAc & ACN \\
\hline RBF & 20 & $9.68^{\mathrm{a}}$ & $6.76^{\mathrm{a}}$ & $5.81^{\mathrm{a}}$ & $7.09^{\mathrm{a}}$ & $10.62^{\mathrm{a}}$ \\
& 25 & $9.46^{\mathrm{a}}$ & $6.66^{\mathrm{a}}$ & $5.73^{\mathrm{a}}$ & $7.15^{\mathrm{a}}$ & $10.49^{\mathrm{a}}$ \\
& 30 & $9.22^{\mathrm{a}}$ & $6.75^{\mathrm{a}}$ & $5.82^{\mathrm{a}}$ & $7.07^{\mathrm{a}}$ & $10.44^{\mathrm{a}}$ \\
APSBF & 20 & $7.97^{\mathrm{b}}$ & $6.19^{\mathrm{a}}$ & $5.60^{\mathrm{a}}$ & $7.31^{\mathrm{a}}$ & $12.74^{\mathrm{b}}$ \\
& 25 & $7.90^{\mathrm{b}}$ & $6.06^{\mathrm{a}}$ & $5.60^{\mathrm{a}}$ & $7.23^{\mathrm{a}}$ & $12.57^{\mathrm{b}}$ \\
& 30 & $7.88^{\mathrm{b}}$ & $6.08^{\mathrm{a}}$ & $5.61^{\mathrm{a}}$ & $7.15^{\mathrm{a}}$ & $12.50^{\mathrm{b}}$ \\
GPSBF & 20 & $8.55^{\mathrm{a}}$ & $6.25^{\mathrm{a}}$ & $6.50^{\mathrm{b}}$ & $8.34^{\mathrm{b}}$ & $13.27^{\mathrm{b}}$ \\
& 25 & $8.36^{\mathrm{a}}$ & $6.08^{\mathrm{a}}$ & $6.41^{\mathrm{b}}$ & $8.15^{\mathrm{b}}$ & $13.24^{\mathrm{b}}$ \\
& 30 & $8.24^{\mathrm{a}}$ & $6.09^{\mathrm{a}}$ & $6.36^{\mathrm{b}}$ & $8.00^{\mathrm{b}}$ & $13.69^{\mathrm{b}}$ \\
& & & & &
\end{tabular}

Values in same column not sharing a common superscript are statistically different $(p<0.05)$

$\Delta G_{s}^{s p}$ specific Gibbs free energy of adsorption, THF tetrahydrofuran, DCM dichloromethane, AC acetone, EtAc ethyl acetate, $A C N$ acetonitrile

\section{Surface morphology}

The BET surface area $\left(S_{B E T}\right)$ and diffusion $(D p)$ were assessed on the samples in order to evaluate changes in the surface morphology, using Eqs. 5-8, and the resulted values can be found in Table 2 . It is possible to observe a significant increase $(p<0.05)$ in the $S_{B E T}$ value upon the organosilane treatments, from 0.23 to up to $1.54 \mathrm{~m}^{2} / \mathrm{g}$. The diffusion parameter $(D p)$ also increases upon organosilane treatment, indicating a higher permeability of the probe to across the sample Table 2).

The cellulose reaction with the organosilane agents can occur on the surface or in the bulk material. If the reaction occurs on the material surface, it can be efficiently available by IGC, by assessing the changes in the surface energy, acid-base character and surface roughness (evaluated by the surface area). On the other hand, if the reaction occurs inside the material, the bulk agents force the fibers apart (Fig. 8), increasing the spatial distance between the cellulose chains, which create new pores in the material. By IGC, this effect can be evaluated by the surface area and diffusion increase.

Thus, in the present study, the increase of the surface area was due to the increase of the roughness and/or due to the increase of the material porosity (Faria et al. 2019). By creating more pores, the gas can flow more and the $D p$ increases, as observed.

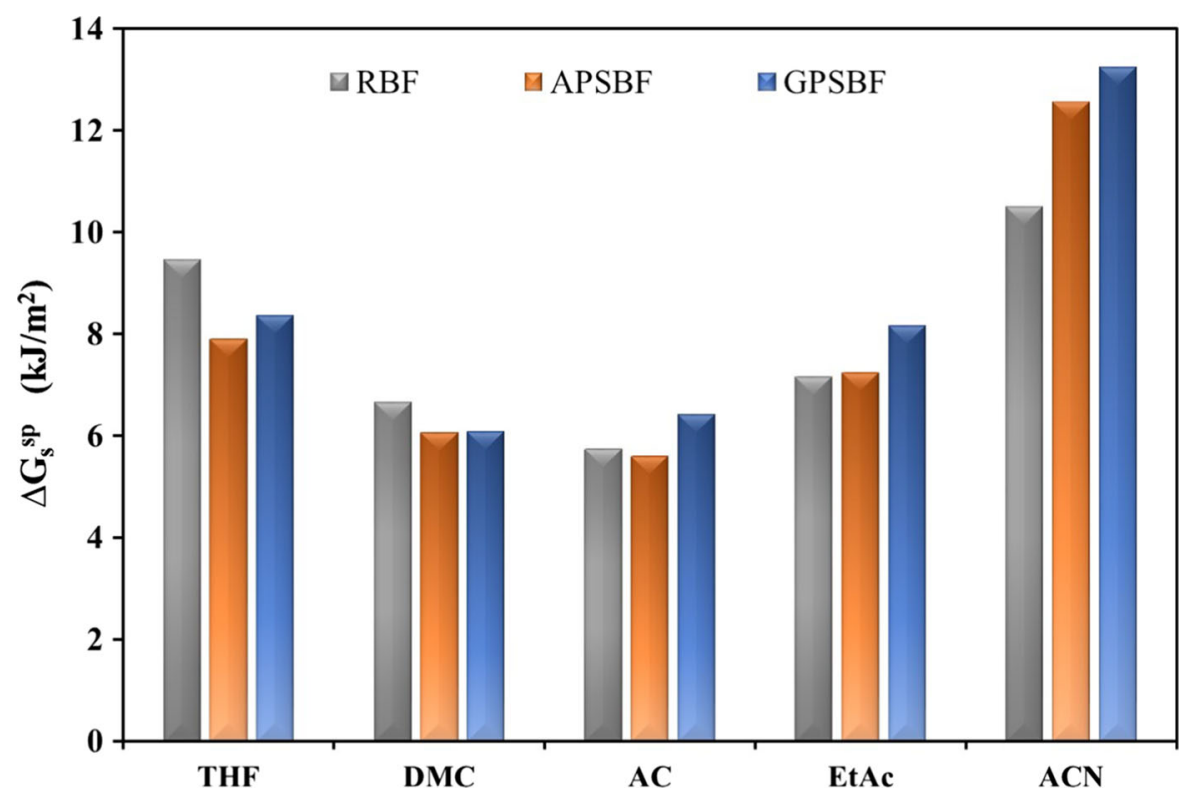

Fig. 7 Specific free energy of adsorption $\left(\Delta \mathrm{G}_{\mathrm{s}}^{\mathrm{sp}}\right)$ of polar probes onto RBF and silane-treated banana fibers with 3-aminopropyltriethoxy silane (APSBF) and glycidoxypropyltrimethoxy silane (GPSBF), at $25^{\circ} \mathrm{C}$. THF tetrahydrofuran, $D C M$ dichloromethane, $A C$ acetone, EtAc ethyl acetate, $A C N$ acetonitrile 

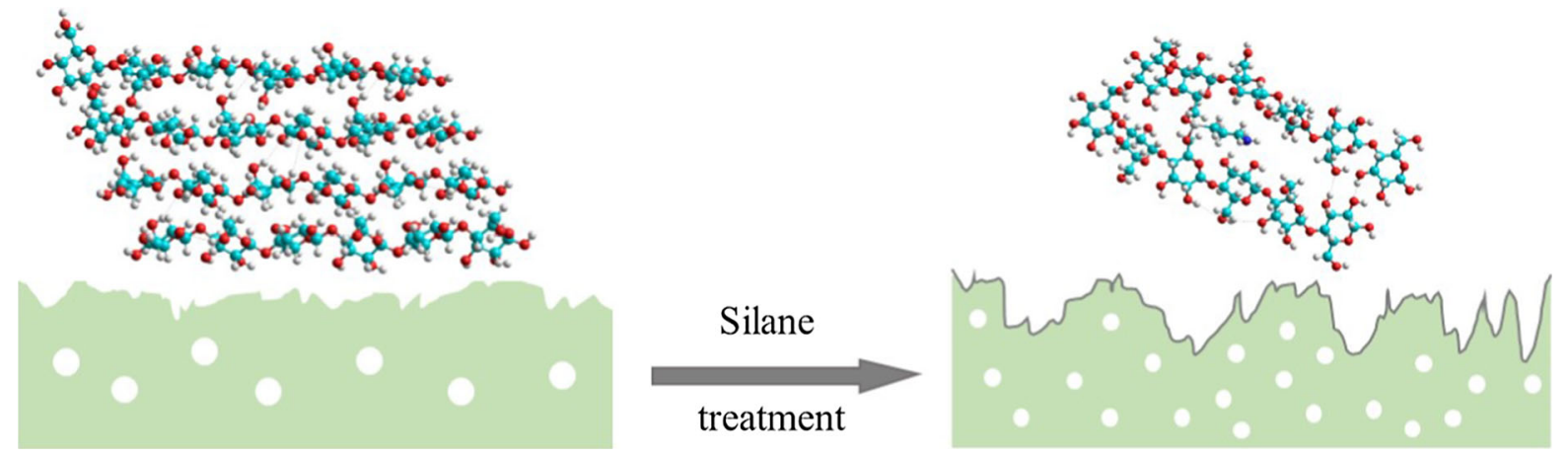

Fig. 8 Schematic representation of silane treatment onto the fibers surface

The porosity and roughness increase for the silanetreated fibers can lead to an increased surface adhesion and cell viability, as shown in the studies presented by Biazar et al. (2011) and Dowling et al. (2011).

\section{Conclusion}

Banana fibers were grafted with organosilane to improve their inherent properties. Additionally, to the FTIR and NMR techniques, currently used to show the reaction between the fibers and organosilane, IGC technique offered a new perspective to evaluate the reaction and the changes occurred during organosilane reactions. In fact, through IGC, it was possible to observe changes at the surface samples, which indicates the presence of the grafting of both organosilane under study. The overall results from this work show that the new material presents a stiffer, rougher and more porous structure, as well as a more basic character, which confer to the banana fibers improved mechanical properties and a more reactive surface. Regarding its application, IGC supports previous data found in literature, where an increased surface roughness and porosity is observed, which could in fact promote cell adhesion.

Acknowledgments The authors would like to thank the National program for Scientific Equipment Renewal, POCI 2010, for sponsoring IGC work (FEDER and Foundation for Science and Technology). The Indian authors would like to thank the Department of Science and Technology, New Delhi for the financial support of the project.

\section{References}

Abdelmouleh M, Boufi S, Salah A, Belgacem M, Gandini A (2002) Interaction of silane coupling agents with cellulose. Langmuir 18:3203-3208

Abdelmouleh M, Boufi S, Belgacem M, Duarte AP, Salah AB, Gandini A (2004) Modification of cellulosic fibres with functionalised silanes: development of surface properties. Int J Biol Macromol 24:43-54

Alonso E, Faria M, Ferreira A, Cordeiro N (2018) Influence of the matrix and polymerization methods on the synthesis of BC/PANi nanocomposites: an IGC study. Cellulose 25:2343-2354

Biazar E, Majid H, Asefnezhad A, Montazeri N (2011) The relationship between cellular adhesion and surface roughness in polystyrene modified by microwave plasma radiation. Int J Nanomed 6:631-639

Brunauer S, Emmet P, Teller E (1938) Adsorption of gases in multimolecular layers. J Am Chem Soc 60:309-319

Cordeiro N, Gouveia C, Moraes AGO, Amico SC (2011) Natural fibers characterization by inverse gas chromatography. Carbohydr Polym 84:110-117

Cordeiro N, Faria M, Abraham E, Pothan L (2013) Assessment of the changes in the cellulosic surface of micro and nano banana fibres due to saponin treatment. Carbohydr Polym 98:1065-1071

Deepa B, Abraham E, Cordeiro N, Mozetic M, Mathew AP, Oksman K, Faria M, Thomas S, Pothan LA (2015) Utilization of various lignocellulosic biomass for the production of nanocellulose: a comparative study. Cellulose 22:1075-1090

Dowling D, Miller I, Adhaoui M, Gallagher W (2011) Effect of surface wettability and topography on the adhesion of osteosarcoma cells on plasma-modified polystyrene. J Biomater Appl 26:327-347

Fan M, Dai D, Huang B (2012) Fourier transform infrared spectroscopy for natural fibres. In: Salih SM (ed) Fourier transform-materials analysis, pp 45-68

Faria M, Vilela C, Silvestre AJD, Deepa B, Resnike M, Freire CSR, Cordeiro N (2019) Physicochemical surface properties of bacterial cellulose/polymethacrylate nanocomposites: an approach by inverse gas chromatography. Carbohydr Polym 206:86-93 
Fernandes SCM, Sadocco P, Alonso-Varona A, Palomare T, Eceiza A, Silvestre AJD, Mondragon I, Freire CSR (2013) Bioinspired antimicrobial and biocompatible bacterial cellulose membranes obtained by surface functionalization with aminoalkyl groups. ACS Appl Mater Interfaces 5:3290-3297

Frone AN, Panaitescu DM, Chiulan J, Nicolae CA, Casarica A, Gabor AR, Trusca R, Damian CM, Purcar V, Alexandrescu E, Stanescu PO (2018) Surface treatment of bacterial cellulose in mild, eco-friendly conditions. Coatings 8:221

Goss K (1997) Considerations about the adsorption of organic molecules from the gas phase to surfaces: implication for inverse gas chromatography and the prediction of adsorption coefficients. J Colloid Interface Sci 190:241-249

Gwon JG, Lee SY, Doh GH, Kim JH (2010) Characterization of chemically modified wood fibers using FTIR spectroscopy for biocomposites. J Appl Polym Sci 116:3212-3219

Hoebbel D, Nacken M, Schmidt H (1998) A NMR study on the hydrolysis, condensation and epoxide ring-opening reaction in sols and gels of the system glycidoxypropyltrimethoxysilane-water-titaniumtetraethoxide. J Sol Gel Sci Technol 12:169-179

Ifuku S, Yano H (2015) Effect of a silane coupling agent on the mechanical properties of a microfibrillated cellulose composite. Int J Biol Macromol 74:428-432

Jackson P, Huglin M (1995) Use of inverse gas chromatography to measure diffusion coefficients in crosslinked polymers at different temperatures. Eur Polym J 31:63-65

Khanjanzadeh H, Behrooz R, Bahramifar N, Altmutter W, Bacher M, Edler M, Griesser T (2018) Surface chemical functionalization of cellulose nanocrystals by 3-aminopropyltriethoxysilane. Int J Biol Macromol 106:1288-1296

Mills R, Gardner D, Wimmer R (2008) Inverse gas chromatography for determining the dispersive surface free energy and acid-base interactions of sheet molding compound-part II 14 ligno-cellulosic fiber types for possible composite reinforcement. J Appl Polym Sci 110:3880-3888

Mohd NH, Ismail NFH, Zahari JI, Fathilah WFW, Kargarzadeh H, Ramli S, Ahmad I, Yarmo MA, Othaman R (2016) Effect of aminosilane modification on nanocrystalline cellulose properties. J Nanomater. Article ID 4804271, 8 p

Oss V (1988) Interfacial Lifshitz-van der Waals and polar interactions in macroscopic system. Chem Rev 88:927-941

Pujiasih S, Masykura A, Kusumaningsih T, Saputra OA (2018) Silylation and characterization of microcrystalline cellulose isolated from indonesian native oil palm empty fruit bunch. Carbohydr Polym 184:74-81
Robles E, Csóka L, Labidi J (2018) Effect of reaction conditions on the surface modification of cellulose nanofibrils with aminopropyl triethoxysilane. Coatings 8:139

Salon M, Abdelmouleh M, Boufi S, Belgacem M, Gandini A (2005) Silane adsorption onto cellulose fibers: hydrolysis and condensation reactions. $\mathrm{J}$ Colloid Interface Sci 289:249-261

Salon M, Gerbaud G, Abdelmouleh M, Bruzzese C, Boufi S, Belgacem M (2007) Studies of interactions between silane coupling agents and cellulose fibers with liquid and solidstate NMR. Magn Reson Chem 45:473-483

Schultz J, Lavielle L, Martin C (1987) The role of the interface in carbon-fibre epoxy composites. J Adhes 23:45-60

Taokaew S, Phisalaphong M, Newby B (2015) Modification of bacterial cellulose with organosilanes to improve attachment and spreading of human fibroblasts. Cellulose 22:2311-2324

Thakur VK, Thakur MK, Gupta RK (2013a) Rapid synthesis of graft copolymers from natural cellulose fibers. Carbohydr Polym 98:820-828

Thakur VK, Thakur MK, Gupta RK (2013b) Synthesis of lignocellulosic polymer with improved chemical resistance through free radical polymerization. Int J Biol Macromol 61:121-126

Thakur VK, Thakur MK, Gupta RK (2013c) Graft copolymers from cellulose: synthesis, characterization and evaluation. Carbohydr Polym 97:18-25

Thakur VK, Thakur MK, Gupta RK (2013d) Development of functionalized cellulosic biopolymers by graft copolymerization. Int J Biol Macromol 62:44-51

Thakur VK, Thakur MK, Gupta RK (2014a) Graft copolymers of natural fibers for green composites. Carbohydr Polym 104:87-93

Thakur MK, Gupta RK, Thakur VK (2014b) Surface modification of cellulose using silane coupling agent. Carbohydr Polym 111:849-855

Thakur MK, Thakur VK, Gupta RK, Pappu A (2016) Synthesis and applications of biodegradable soy based graft copolymers: a review. ACS Sustain Chem Eng 4:1-17

Thielmann F (2004) Introduction into the characterization of porous materials by inverse gas chromatography. J Chromatogr A 1037:115-123

Xie Y, Hill C, Xiao Z, Militz H, Mai C (2010) Silane coupling agents used for natural fiber/polymer composites: a review. Compos Part A 41:806-819

Publisher's Note Springer Nature remains neutral with regard to jurisdictional claims in published maps and institutional affiliations. 